\title{
Residual Lung Function Impairment Is Associated with Hyperventilation in Patients Recovered from Hospitalised COVID-19: A Cross-Sectional Study
}

\author{
Ernesto Crisafulli ${ }^{1,2, *}$, , Daniele Gabbiani ${ }^{2}$, Giulia Magnani ${ }^{2}$, Gianluigi Dorelli ${ }^{3}$, Fabiana Busti ${ }^{2}$, \\ Giulia Sartori ${ }^{1,2}$, Gianenrico Senna ${ }^{4}$, Domenico Girelli ${ }^{2}$ (I) and on behalf of the RESPICOVID \\ Study Investigators ${ }^{\dagger}$
}

Citation: Crisafulli, E.; Gabbiani, D.; Magnani, G.; Dorelli, G.; Busti, F.; Sartori, G.; Senna, G.; Girelli, D.; the RESPICOVID Study Investigators. Residual Lung Function Impairment Is Associated with Hyperventilation in Patients Recovered from Hospitalised COVID-19: A Cross-Sectional Study. J. Clin. Med. 2021, 10, 1036. https://doi.org/ $10.3390 /$ jcm10051036

Academic Editor: David J. Barnes

Received: 20 January 2021

Accepted: 23 February 2021

Published: 3 March 2021

Publisher's Note: MDPI stays neutral with regard to jurisdictional claims in published maps and institutional affiliations.

Copyright: (c) 2021 by the authors. Licensee MDPI, Basel, Switzerland. This article is an open access article distributed under the terms and conditions of the Creative Commons Attribution (CC BY) license (https:/ / creativecommons.org/licenses/by/ $4.0 /)$.
1 Respiratory Medicine Unit, Department of Medicine, University of Verona and Azienda Ospedaliera Universitaria Integrata of Verona, 37126 Verona, Italy; giulia.sartori.verona@gmail.com

2 Department of Medicine, Section of Internal Medicine, University of Verona and Azienda Ospedaliera Universitaria Integrata of Verona, 37126 Verona, Italy; daniele.gabbiani@yahoo.com (D.G.); giuliamagnani1@gmail.com (G.M.); fabiana.busti@univr.it (F.B.); domenico.girelli@univr.it (D.G.)

3 School of Medicine in Sports and Exercise, University of Verona, 37129 Verona, Italy; gianluigi.dorelli@gmail.com

4 Department of Medicine, Allergy and Clinical Immunology Section, University of Verona and Azienda Ospedaliera Universitaria Integrata of Verona, 37126 Verona, Italy; gianenrico.senna@univr.it

* Correspondence: ernesto.crisafulli@univr.it

+ Membership of the RESPICOVID study investigators is provided in Acknowledgments.

\begin{abstract}
Patients who have recovered from COVID-19 show persistent symptoms and lung function alterations with a restrictive ventilatory pattern. Few data are available evaluating an extended period of COVID-19 clinical progression. The RESPICOVID study has been designed to evaluate patients' pulmonary damage previously hospitalised for interstitial pneumonia due to COVID-19. We focused on the arterial blood gas (ABG) analysis variables due to the initial observation that some patients had hypocapnia (arterial partial carbon dioxide pressure- $\mathrm{PaCO}_{2} \leq 35 \mathrm{mmHg}$ ). Therefore, we aimed to characterise patients with hypocapnia compared to patients with normocapnia $\left(\mathrm{PaCO}_{2}>35 \mathrm{mmHg}\right)$. Data concerning demographic and anthropometric variables, clinical symptoms, hospitalisation, lung function and gas-analysis were collected. Our study comprised 81 patients, of whom 19 (24\%) had hypocapnia as compared to the remaining $(n=62,76 \%)$, and defined by lower levels of $\mathrm{PaCO}_{2}$, serum bicarbonate $\left(\mathrm{HCO}^{3-}\right)$, carbon monoxide diffusion capacity $\left(\mathrm{DL}_{\mathrm{CO}}\right)$, and carbon monoxide transfer coefficient $\left(\mathrm{K}_{\mathrm{CO}}\right)$ with an increased level of $\mathrm{pH}$ and arterial partial oxygen pressure $\left(\mathrm{PaO}_{2}\right) . \mathrm{K}_{\mathrm{CO}}$ was directly correlated with $\mathrm{PaCO}_{2}$ and inversely with $\mathrm{pH}$. In our preliminary report, hypocapnia is associated with a residual lung function impairment in diffusing capacity. We focus on ABG analysis's informativeness in the follow-up of post-COVID patients.
\end{abstract}

Keywords: COVID-19; lung function; hypocapnia; hyperventilation; restrictive pattern; interstitial pneumonia

\section{Introduction}

A total of eighty-seven percent of patients who have recovered from COVID-19 show persistent symptoms at 60 days, particularly fatigue and dyspnea [1]. Lung function impairments with a reduction of the carbon monoxide diffusion capacity ( $\mathrm{DL}_{\mathrm{CO}}$ ) has been evident at discharge [2] and during the early convalescence phase of patients recovered from COVID-19 [3]; the carbon monoxide transfer coefficient $\left(\mathrm{K}_{\mathrm{CO}}\right)$ alterations might better characterise the gas exchange efficiency [4]. Few data are available evaluating a more extended period of COVID-19 clinical progression, particularly the oxygenation level and the ventilatory pattern at rest. Our preliminary report focused on variables related to the arterial blood gas (ABG) analysis and characterised patients with specific alterations. This interest raised 
from the initial observation that some post-COVID patients had hypocapnia, documented by lower levels $(\leq 35 \mathrm{mmHg})$ of arterial partial carbon dioxide pressure $\left(\mathrm{PaCO}_{2}\right)$. Any technical bias has been excluded, and several patients repeated blood sample to confirm the results. Aim of our study was, therefore, to characterise patients with hypocapnia $\left(\mathrm{PaCO}_{2} \leq 35 \mathrm{mmHg}\right)$ in comparison to patients with normocapnia $\left(\mathrm{PaCO}_{2}>35 \mathrm{mmHg}\right)$.

\section{Materials and Methods}

At our tertiary hospital (AOUI Verona, Verona, Italy), we have organised a dedicated outpatient clinic for adult patients previously hospitalised for interstitial pneumonia due to COVID-19, with or without respiratory failure. The RESPICOVID study, a prospective observational trial, has been designed to comprehensively evaluate the prevalence, clinical impact, and predictive factors of pulmonary damage in patients recovered from COVID-19. Due to the explorative nature of our study and the feasibility of observations derived, here we report some aspects related to preliminary data. For this reason, no formal sample size calculation was made and we had not a comparison group of not exposed (controls without COVID-19). The study has been described according to a cross-sectional design, following the STROBE guidelines. The local Ethics Committee approved the study protocol (No. 2785CESC), according to the Good Clinical Practice recommendations and the requirements of the Declaration of Helsinki. Written informed consent was obtained from all participants.

All consecutive patients discharged were considered, excluding those unable to reach the outpatient service (e.g., permanently bedridden) or perform tests (e.g., severe cognitive impairment). All measures were collected prospectively beginning on 6 July 2020, 4 months after patients' discharge (median time 127 days, standard deviation [SD] 18 days). The ABG analysis has been performed in all patients enrolled, at rest, in-room air and quiet condition.

We recorded demographic and anthropometric variables, clinical symptoms, laboratory, and gas-analysis. Values of arterial partial oxygen pressure $\left(\mathrm{PaO}_{2}\right)$ were also standardised $\left(s t \mathrm{PaO}_{2}\right)$ according to the lower levels of $\mathrm{PaCO}_{2}(<40 \mathrm{mmHg})$ by the following formula:

$$
s t \mathrm{PaO}_{2}=\left[\left(\mathrm{PaCO}_{2} \cdot 1.66\right)+\mathrm{PaO}_{2}\right]-66.4 \text {. }
$$

Data from hospitalisation for COVID-19 were also compared [5].

Lung function was performed according to the international recommendations [6]; a flow-sensing spirometer connected to a computer for data analysis (Jaeger MasterScreen PFT System) was used for the measurements. Forced vital capacity (FVC), forced expiratory volume in the first second $\left(\mathrm{FEV}_{1}\right)$, and total lung capacity (TLC) were recorded. $\mathrm{FEV}_{1} / \mathrm{FVC}$ ratio was taken as the index of airflow obstruction. DLCO and $\mathrm{KCO}$ were measured by the single breath method. $\mathrm{FEV}_{1}, \mathrm{FVC}, \mathrm{TLC}, \mathrm{DLCO}$ and $\mathrm{KCO}$ were expressed as percentages of the predicted values $[7,8]$.

Data are reported with numbers (percentages) for categorical variables, mean (SD) or median (first quartile; third quartile) for continuous variables with a normal or non-normal distribution, respectively. A preliminary Shapiro-Wilk test was performed. Categorical variables were compared by the $\chi^{2}$ test or the Fisher exact test, while continuous variables were assessed by the independent $t$-test or the non-parametric Mann-Whitney test. Pearson $(\mathrm{r})$ and Spearman $(\rho)$ correlations have been carried-out between variables. All analyses were performed using IBM SPSS, version 25.0 (IBM Corp., Armonk, NY, USA), with $p$ values of $<0.05$ considered statistically significant.

\section{Results}

Our preliminary report comprised 81 patients, of whom $19(24 \%)$ had hypocapnia as compared to the remaining $(n=62,76 \%)$, and defined by lower levels of $\mathrm{PaCO}_{2}$, serum bicarbonate $\left(\mathrm{HCO}^{3-}\right), \mathrm{DL}_{\mathrm{CO}}$, and $\mathrm{K}_{\mathrm{CO}}$ with an increased level of $\mathrm{pH}$ and arterial partial oxygen pressure $\left(\mathrm{PaO}_{2}\right)$. Comparing data from hospitalisation, hypocapnic patients had lower $\mathrm{PaCO}_{2}$ and $\mathrm{HCO}^{3-}$ (Table 1). $\mathrm{K}_{\mathrm{CO}}$ was directly correlated with $\mathrm{PaCO}_{2}$ and inversely with $\mathrm{pH} ; \mathrm{PaCO}_{2}$ was directly correlated with $\mathrm{PaCO}_{2}$ at hospitalisation (Figure 1). 
Table 1. Characteristics of patients considered.

\begin{tabular}{|c|c|c|c|c|}
\hline Variables & $\begin{array}{l}\text { All Patients } \\
\qquad(N=81)\end{array}$ & $\begin{array}{l}\text { Patients with Normocapnia } \\
\qquad(N=62)\end{array}$ & $\begin{array}{l}\text { Patients with Hypocapnia } \\
\qquad(N=19)\end{array}$ & $p$ Value \\
\hline Age, years & $66.5 \pm 11.2$ & $67.2 \pm 10.7$ & $64.4 \pm 12.5$ & $0.353^{a}$ \\
\hline Male, $n(\%)$ & $54(67)$ & $39(63)$ & $15(79)$ & $0.194^{b}$ \\
\hline $\mathrm{BMI}, \mathrm{kg} \cdot \mathrm{m}^{2}$ & $27(24.4-30)$ & $27.1(24.3-30.7)$ & $26.9(25-29.2)$ & $0.705^{c}$ \\
\hline $\begin{array}{c}\text { Smoking habit, } \\
\text { no/current or former, } n(\%)\end{array}$ & $46(57) / 35(43)$ & $37(60) / 25(40)$ & $9(47) / 10(53)$ & $0.343^{b}$ \\
\hline Arterial hypertension, $n(\%)$ & $46(57)$ & $34(55)$ & $12(63)$ & $0.522^{b}$ \\
\hline Diabetes mellitus, $n(\%)$ & $10(12)$ & $8(13)$ & $2(10)$ & $>0.999^{d}$ \\
\hline Cough, $n(\%)$ & $9(11)$ & $8(13)$ & $1(5)$ & $0.678^{d}$ \\
\hline Extensional dyspnea, $n(\%)$ & $16(20)$ & $13(21)$ & $3(16)$ & $0.751^{d}$ \\
\hline Asthenia, $n(\%)$ & $27(33)$ & $20(32)$ & $7(37)$ & $0.711^{b}$ \\
\hline Muscle fatigue, $n(\%)$ & $19(24)$ & $15(24)$ & $4(21)$ & $>0.999^{d}$ \\
\hline Heart rate, bpm & $69.8 \pm 10.5$ & $69.9 \pm 10.3$ & $69.8 \pm 11.4$ & $0.967^{\mathrm{a}}$ \\
\hline Respiratory rate, bpm & $16(14-20)$ & $16(14-20)$ & $16(13.5-20)$ & $0.543^{c}$ \\
\hline $\mathrm{SpO}_{2}, \%$ & $97(96,97)$ & $97(96,97)$ & $97(96-98)$ & $0.093^{c}$ \\
\hline $\mathrm{pH}$ & $7.43(7.41-7.44)$ & $7.42(7.41-7.44)$ & $7.44(7.43-7.46)$ & $0.002^{c}$ \\
\hline $\mathrm{PaCO}_{2}, \mathrm{mmHg}$ & $38(36-40)$ & $39(37-41)$ & $34(32-34)$ & $<0.001^{c}$ \\
\hline $\mathrm{PaO}_{2}, \mathrm{mmHg}$ & $96.3 \pm 12.8$ & $94.1 \pm 12.3$ & $103.2 \pm 12.1$ & $0.007^{a}$ \\
\hline $\mathrm{PaO}_{2} / \mathrm{FiO}_{2}$ & $458.3 \pm 61$ & $448.3 \pm 58.8$ & $491.2 \pm 57.9$ & $0.007^{a}$ \\
\hline $\mathrm{PaO}_{2} / \mathrm{FiO}_{2} \leq 400 \mathrm{e}, n(\%)$ & $15(18)$ & $14(23)$ & $1(5)$ & $0.173^{d}$ \\
\hline$s t \mathrm{PaO}_{2}, \mathrm{mmHg}$ & $91.7 \pm 11.9$ & $91.9 \pm 12.2$ & $91.3 \pm 11.2$ & $0.884^{\mathrm{a}}$ \\
\hline $\mathrm{P}(\mathrm{A}-\mathrm{a}) \mathrm{O}_{2}, \mathrm{mmHg}$ & $6.04 \pm 12.1$ & $6.29 \pm 12.5$ & $5.25 \pm 11.2$ & $0.747^{\mathrm{a}}$ \\
\hline $\mathrm{HCO}^{3-}, \mathrm{mmol} / \mathrm{L}$ & $25 \pm 2$ & $25.8 \pm 1.6$ & $22.7 \pm 1.4$ & $<0.001^{a}$ \\
\hline C-reactive protein, $\mathrm{mg} / \mathrm{L}$ & $1(1,2)$ & $1(1,2)$ & $1(1-4)$ & $0.926^{\mathrm{c}}$ \\
\hline Haemoglobin, g/dL & $14.1 \pm 1.5$ & $14.1 \pm 1.5$ & $14 \pm 1.7$ & $0.907^{\mathrm{a}}$ \\
\hline Platelets, $10^{9} / \mathrm{L}$ & $209.8 \pm 48.7$ & $211.2 \pm 52.3$ & $204.9 \pm 33.7$ & $0.664^{\mathrm{a}}$ \\
\hline Leucocytes, $10^{9} / \mathrm{L}$ & $6.1 \pm 1.5$ & $5.98 \pm 1.5$ & $6.13 \pm 1.3$ & $0.710^{\mathrm{a}}$ \\
\hline $\mathrm{FEV}_{1}, \%$ predicted & $120 \pm 21.1$ & $122.2 \pm 21.6$ & $112.4 \pm 17.6$ & $0.093^{a}$ \\
\hline FVC, $\%$ predicted & $120(110.2-140.7)$ & $121(112-141)$ & $118(96-139)$ & $0.226^{c}$ \\
\hline $\mathrm{FEV}_{1} / \mathrm{FVC}, \%$ & $101(98-106)$ & $102(98-107)$ & $100(94-103)$ & $0.073^{c}$ \\
\hline TLC, \% predicted & $100.5 \pm 13.3$ & $101 \pm 13.7$ & $98.7 \pm 12.1$ & $0.547^{\mathrm{a}}$ \\
\hline $\mathrm{DL}_{\mathrm{CO}}, \%$ predicted & $86.4 \pm 16.5$ & $88.6 \pm 16.3$ & $78.5 \pm 15.3$ & $0.034^{a}$ \\
\hline $\mathrm{K}_{\mathrm{CO}}, \%$ predicted & $94.9 \pm 17.2$ & $97.2 \pm 17.4$ & $86.5 \pm 13.6$ & $0.032^{a}$ \\
\hline \multicolumn{5}{|l|}{$\begin{array}{l}\text { Variables measured at } \\
\text { hospitalisation for COVID-19 }\end{array}$} \\
\hline $\mathrm{pH}^{\mathrm{f}}(N=64)$ & $7.47(7.44-7.50)$ & $7.48(7.45-7.50)$ & $7.47(7.43-7.50)$ & $0.394^{c}$ \\
\hline $\mathrm{PaCO}_{2}, \mathrm{mmHg}^{\mathrm{f}}(\mathrm{N}=64)$ & $33(31-35)$ & $34(32-35)$ & $31(27-33)$ & $0.010^{c}$ \\
\hline $\mathrm{PaO}_{2} / \mathrm{FiO}_{2}^{\mathrm{f}}(N=64)$ & $288.8 \pm 86.6$ & $284.9 \pm 90.5$ & $301.5 \pm 73.5$ & $0.522^{a}$ \\
\hline $\begin{array}{c}\mathrm{PaO}_{2} / \mathrm{FiO}_{2} \leq 300^{\mathrm{f}}(\mathrm{N}=64) \\
n(\%)\end{array}$ & $37(58)$ & $31(63)$ & $6(40)$ & $0.110^{b}$ \\
\hline
\end{tabular}


Table 1. Cont.

\begin{tabular}{|c|c|c|c|c|}
\hline Variables & $\begin{array}{l}\text { All Patients } \\
\qquad(N=81)\end{array}$ & $\begin{array}{l}\text { Patients with Normocapnia } \\
\qquad(N=62)\end{array}$ & $\begin{array}{l}\text { Patients with Hypocapnia } \\
\qquad(N=19)\end{array}$ & $p$ Value \\
\hline $\operatorname{stPaO} 2 / \mathrm{FiO}_{2}{ }^{\mathrm{f}}(N=64)$ & $234.4 \pm 86.4$ & $236.3 \pm 92.8$ & $228.2 \pm 63.7$ & $0.752^{a}$ \\
\hline $\mathrm{P}(\mathrm{A}-\mathrm{a}) \mathrm{O}_{2}, \mathrm{mmHg}^{\mathrm{f}}(\mathrm{N}=64)$ & $46.1(37.4-66.5)$ & $45.7(36.2-66.5)$ & $46.5(37.5-69.7)$ & $0.890^{c}$ \\
\hline $\mathrm{HCO}^{3-}, \mathrm{mmol} / \mathrm{L}^{\mathrm{f}}(N=64)$ & $23.9 \pm 2.9$ & $24.7 \pm 2.1$ & $21.6 \pm 3.8$ & $<0.001^{a}$ \\
\hline Length of stay, days & $8.1(5-13.5)$ & $8(5-14)$ & $11(5-13)$ & $0.369^{c}$ \\
\hline $\begin{array}{l}\text { Unit of admission, } \\
\text { ICU/medical ward, } n(\%)\end{array}$ & $12(15) / 69(85)$ & $10(16) / 52(84)$ & $2(10) / 17(90)$ & $0.722^{d}$ \\
\hline Pulmonary embolism, $n(\%)$ & $3(4.5)$ & $3(5.7)$ & $0(0)$ & $>0.999^{d}$ \\
\hline Oxygen-therapy, $n(\%)$ & $52(64)$ & $40(64)$ & $12(63)$ & $0.914^{b}$ \\
\hline Lopinavir/ritonavir, $n(\%)$ & $60(74)$ & $44(71)$ & $16(84)$ & $0.372^{d}$ \\
\hline Hydroxychloroquine, $n(\%)$ & $65(80)$ & $48(77)$ & $17(89)$ & $0.335^{d}$ \\
\hline Antibiotics, $n(\%)$ & $22(27)$ & $16(26)$ & $6(32)$ & $0.621^{b}$ \\
\hline Tocilizumab, $n(\%)$ & $16(20)$ & $11(18)$ & $5(26)$ & $0.511^{d}$ \\
\hline Steroids, $n(\%)$ & $22(27)$ & $14(23)$ & $8(42)$ & $0.094^{b}$ \\
\hline Prophylactic LMWH, $n(\%)$ & $26(41)$ & $22(45)$ & $4(27)$ & $0.208^{\mathrm{d}}$ \\
\hline
\end{tabular}

Data are shown as mean \pm standard deviation, median $\left[25^{\circ}-75^{\circ}\right.$ percentiles], or number (percentages). In bold, significant variables. ${ }^{a}$ calculated by the independent $t$-test; ${ }^{\mathrm{b}}$ calculated by the $\chi^{2}$ test; ${ }^{\mathrm{c}}$ calculated by the non-parametric Mann-Whitney test; ${ }^{\mathrm{d}}$ calculated by the Fisher exact test; ${ }^{\mathrm{e}}$ Defined as the normality limit; ${ }^{\mathrm{f}}$ Data collected at admission in the emergency room and in spontaneous breathing. Atrial fibrillation, ischemic heart disease, vascular disease, chronic heart failure, cancer, chronic kidney disease, liver disease, chronic obstructive pulmonary disease, asthma, and connective-disease have a prevalence of $<10 \%$ with no significant difference between groups. Abbreviations: $\mathrm{BMI}$ define body mass index; $\mathrm{SpO}_{2}$, oxygen saturation by pulse oximetry; $\mathrm{PaCO}_{2}$, arterial partial carbon dioxide pressure; $\mathrm{PaO}_{2}$, arterial partial oxygen pressure; st $\mathrm{PaO}_{2}$, standardised arterial partial oxygen pressure; $\mathrm{PaO}_{2} / \mathrm{FiO}_{2}$, the ratio of the partial pressure of arterial oxygen to the fraction of inspired oxygen; $\mathrm{P}(\mathrm{A}-\mathrm{a}) \mathrm{O}_{2}$, alveolar-arterial gradient; $\mathrm{HCO}^{3-}$ serum bicarbonate; $\mathrm{FEV}_{1}$, forced expiratory

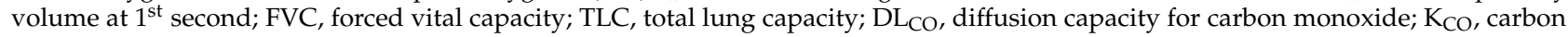
monoxide transfer coefficient; ICU, intensive care unit; LMWH, low molecular weight heparin.
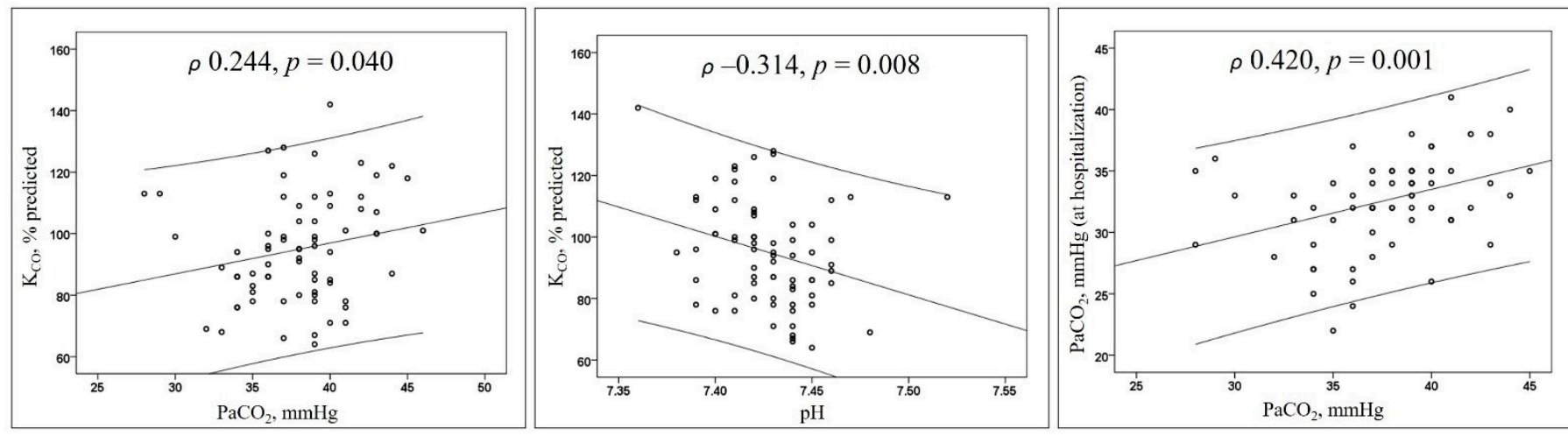

Figure 1. Scatterplots. Lines represent the regression with the $95 \%$ confidence intervals. Abbreviations: $\mathrm{K}_{\mathrm{CO}}$ represents the carbon monoxide transfer coefficient; $\mathrm{PaCO}_{2}$, arterial partial carbon dioxide pressure.

\section{Discussion}

Although lung function alterations in term of diffusion impairment in our patients are in line with other reports [2,3], our is the first report examining ABG in patients with COVID-19 pneumonia in a long interval from hospital discharge ( $>4$ months). We report that nearly one-fourth of patients recovered from an interstitial pneumonia COVID-19 have hypocapnia, present at the moment of hospitalisation and associated with a restrictive residual pattern.

Several pulmonary disorders such as pneumonia, pulmonary embolism, asthma or interstitial lung disease (ILD) may produce hypocapnia; the leading physiologic cause of the 
reduction of $\mathrm{PaCO}_{2}$ is related to hyperventilation [9]. Severe interstitial pneumonia due to COVID-19 cause hypoxaemia with mechanisms related to intrapulmonary shunt (oedema and atelectasis), loss of lung perfusion regulation, intravascular microthrombi and impaired diffusion capacity [10]. Although shunt and a low ratio of the alveolar ventilation to blood flow $\left(\mathrm{V}_{\mathrm{A}} / \mathrm{Q}\right)$ mismatch are the most frequent causes of hypoxaemia, diffusion limitation may cause hypoxemia also in the absence of $\mathrm{V}_{\mathrm{A}} / \mathrm{Q}$ mismatch [11]. Moreover, lung units with hypoperfusion due to intravascular deficits increase the alveolar dead space with poor ventilation [11]: as a consequence, to maintain a normal arterial $\mathrm{PaCO}_{2}$ the respiratory drive increase the minute ventilation primarily by increasing tidal volume (hyperpnea) and respiratory rate (tachypnea) [10,11]. At hospitalisation for COVID-19, 37 of our patients $(58 \%)$ had a severe hypoxaemic respiratory failure $\left(\mathrm{PaO}_{2} / \mathrm{FiO}_{2} \leq 300\right)$ but with no residual hypocapnia differences. Similarly, the correction of oxygen pressure by the $s t \mathrm{PaO}_{2}$, such as other data concerning oxygenation at hospitalisation and in the recovery phase seems to be little associated with hypocapnia. Mechanical adaptation to the increased elastic work of breathing or a reflex-mediated originating from the chest wall receptors may be a resting hyperventilation mechanism, which probably starts in our patients from hospitalisation. However, we cannot exclude the possibility of an increased virus-induced respiratory drive stimulation, explaining the long-time persistence of hypocapnia. Notably, hyperventilation has no impact on clinical symptoms perceived from patients and concerning in particular extensional dyspnea; other causes of symptom perception will probably have to be sought.

In other ILD conditions, not COVID-19, the association of hypocapnia regardless hypoxemia has been reported. Hypocapnia induced by resting hyperventilation has been observed in asbestos-exposed subjects with a restrictive disorder related to mild pleural plaques [12]. Moreover, in patients having ILD associated with polymyositis and dermatomyositis, hypocapnia's presence increases the probability of a worse prognosis in 6 months [13]. A restrictive ventilatory defect with a reduction of DLCO has been documented in patients recovered from COVID-19 [2,3], closely related to the severity of infection [3]. In our patients, the presence of hypocapnia is associated with a residual lung function impairment in term of diffusing capacity.

Our major strengths are the originality of considerations, the prospective and consecutive data collection. As limitations, we should mention the relatively small sample size and controls missing: our considerations need to be confirmed in a large study cohort with matched-controls without COVID-19.

\section{Conclusions}

In conclusion, our report highlights the hypocapnia as a marker of residual lung function impairment of patients recovered from hospitalised COVID-19; moreover, we focus on ABG analysis's informativeness in these patients' follow-up.

Author Contributions: Conceptualization, E.C., D.G. (Daniele Gabbiani); methodology, E.C., D.G. (Daniele Gabbiani); formal analysis, E.C.; data curation, E.C., D.G. (Daniele Gabbiani), G.M., G.D., F.B., G.S. (Giulia Sartori); writing-original draft preparation, E.C., G.D., G.S. (Gianenrico Senna), D.G. (Domenico Girelli); writing-review and editing, E.C., F.B., G.S. (Gianenrico Senna), D.G. (Domenico Girelli). All authors have read and agreed to the published version of the manuscript. All the other RESPICOVID investigators have participated to the data curation.

Funding: This work was supported by a grant from the Cariverona Foundation (ENACT project).

Institutional Review Board Statement: The study was conducted according to the guidelines of the Declaration of Helsinki, and approved by the local Ethics Committee of Verona e Rovigo (protocol code no. 2785CESC, approval date 10 June 2020.

Informed Consent Statement: Informed consent was obtained from all subjects involved in the study.

Data Availability Statement: The data presented in this study are available on request from the corresponding author. 
Acknowledgments: We are indebted to all medical and nursing colleagues for their assistance and cooperation in this study. The RESPICOVID study investigators are: Ernesto Crisafulli (Principal Investigator) and in al-phabetical order Maria Chiara Ambrosetti, Marco Bodini, Francesco Bordin, Silvia Bozzetti, Michele Braggio, Fabiana Busti, Marco Caminati, Luca Dalle Carbonare, Gianluigi Dorelli, Angela Federico, Marcello Ferrari, Sergio Ferrari, Armando Fiore, Daniele Gabbiani, Domenico Girelli, Lucia Guidolin, Elettra Libener, Andrea Lobba, Giulia Magnani, Giancarlo Mansueto, Elisa Mantovani, Giacomo Marchi, Sara Mariotto, Alessio Maroccia, Claudio Micheletto, Francesca Nalin, Laura Sagramoni, Giulia Sartori, Gianenrico Senna, Francesca Stefani, Stefano Tamburin, Virginia Trevisan, Rachele Vaia, Maria Teresa Valenti, Alice Vianello, Alessandro Vignola, Donato Zipeto from the University of Verona and Azienda Ospedaliera Universitaria Integrata of Verona, Verona, Italy.

Conflicts of Interest: The authors declare no conflict of interest. The funders had no role in the design of the study; in the collection, analyses, or interpretation of data; in the writing of the manuscript, or in the decision to publish the results.

\section{References}

1. Carfi, A.; Bernabei, R.; Landi, F. Gemelli against COVID-19 Post-Acute Care Study Group. Persistent Symptoms in Patients after Acute COVID-19. JAMA 2020, 324, 603-605. [CrossRef]

2. Mo, X.; Jian, W.; Su, Z.; Chen, M.; Peng, H.; Peng, P.; Lei, C.; Chen, R.; Zhong, N.; Li, S. Abnormal pulmonary function in COVID-19 patients at time of hospital discharge. Eur. Respir. J. 2020, 55, 2001217. [CrossRef]

3. Huang, Y.; Tan, C.; Wu, J.; Chen, M.; Wang, Z.; Luo, L.; Zhou, X.; Liu, X.; Huang, X.; Yuan, S.; et al. Impact of coronavirus disease 2019 on pulmonary function in early convalescence phase. Respir. Res. 2020, 21, 163. [CrossRef]

4. Nusair, S. Abnormal carbon monoxide diffusion capacity in COVID-19 patients at time of hospital discharge. Eur. Respir. J. 2020, 56, 2001832. [CrossRef]

5. Prediletto, R.; Paoletti, P.; Fornai, E.; Perissinotto, A.; Petruzzelli, S.; Formichi, B.; Ruschi, S.; Palla, A.; Giannella-Neto, A.; Giuntini, C. Natural course of treated pulmonary embolism. Evaluation by perfusion lung scintigraphy, gas exchange, and chest roentgenogram. Chest 1990, 97, 554-561. [CrossRef]

6. Miller, M.R.; Hankinson, J.; Brusasco, V.; Burgos, F.; Casaburi, R.; Coates, A.; Crapo, R.; Enright, P.; van der Grinten, C.P.; Gustafsson, P.; et al. ATS/ERS Task Force. Standardisation of spirometry. Eur. Respir. J. 2005, 26, 319-338. [CrossRef]

7. Quanjer, P.H.; Tammeling, G.J.; Cotes, J.E.; Pedersen, O.; Perlin, R.; Yernault, J. Lung volumes and forced ventilatory flows. Report Working Party Standardization of Lung Function Tests, European Community for Steel and Coal. Official Statement of the European Respiratory Society. Eur. Respir. J. Suppl. 1993, 16, 5-40.

8. Cotes, J.E.; Chinn, D.J.; Quanjer, P.H.; Roca, J.; Yernault, J.C. Standardisation of the measurement of transfer factor (diffusing capacity). Report Working Party Standardization of Lung Function Tests, European Community for Steel and Coal. Official Statement of the European Respiratory Society. Eur. Respir. J. Suppl. 1993, 16, 41-52.

9. Laffey, J.G.; Kavanagh, B.P. Hypocapnia. N. Engl. J. Med. 2002, 347, 43-53. [CrossRef]

10. Dhont, S.; Derom, E.; Van Braeckel, E.; Depuydt, P.; Lambrecht, B.N. The pathophysiology of 'happy' hypoxemia in COVID-19. Respir. Res. 2020, 21, 198. [CrossRef]

11. Petersson, J.; Glenny, R.W. Gas exchange and ventilation-perfusion relationships in the lung. Eur. Respir. J. 2014, 44, 1023-1041. [CrossRef]

12. Dujić, Z.; Eterović, D.; Tocilj, J. Association between asbestos-related pleural plaques and resting hyperventilation. Scand. J. Work Environ. Health 1993, 19, 346-351. [CrossRef]

13. Sugiyama, Y.; Yoshimi, R.; Tamura, M.; Takeno, M.; Kunishita, Y.; Kishimoto, D.; Yoshioka, Y.; Kobayashi, K.; Takase-Minegishi, K.; Watanabe, T.; et al. The predictive prognostic factors for polymyositis/dermatomyositis-associated interstitial lung disease. Arthritis Res. Ther. 2018, 20, 7. [CrossRef] 